\title{
Mobility of electrostatically and sterically stabilized gold nanoparticles (AuNPs) in saturated porous media
}

Fjordbøge, Annika Sidelmann; Uthuppu, Basil; Jakobsen, Mogens Havsteen; Fischer, Søren Vang; Broholm, Mette Martina

\section{Published in:}

Environmental science and pollution research international

Link to article, DOI:

$10.1007 / \mathrm{s} 11356-019-06132-8$

Publication date:

2019

Document Version

Peer reviewed version

Link back to DTU Orbit

Citation (APA):

Fjordbøge, A. S., Uthuppu, B., Jakobsen, M. H., Fischer, S. V., \& Broholm, M. M. (2019). Mobility of electrostatically and sterically stabilized gold nanoparticles (AüNPs) in saturated porous media. Environmental science and pollution research international, 26(28), [29460-29472]. https://doi.org/10.1007/s11356-019-061328

\section{General rights}

Copyright and moral rights for the publications made accessible in the public portal are retained by the authors and/or other copyright owners and it is a condition of accessing publications that users recognise and abide by the legal requirements associated with these rights.

- Users may download and print one copy of any publication from the public portal for the purpose of private study or research.

- You may not further distribute the material or use it for any profit-making activity or commercial gain

- You may freely distribute the URL identifying the publication in the public portal 
Mobility of electrostatically and sterically stabilized gold nanoparticles (AuNPs) in saturated porous media

Annika S. Fjordbøge ${ }^{\mathrm{a}, *}$, Basil Uthuppu ${ }^{\mathrm{b}}$, Mogens H. Jakobsen ${ }^{\mathrm{b}}$, Søren V. Fischer ${ }^{\mathrm{b}}$, Mette M. Broholm ${ }^{\mathrm{a}}$ ${ }^{a}$ Department of Environmental Engineering, Technical University of Denmark, Miljøvej, Building 113, 2800 Kgs. Lyngby, Denmark; ${ }^{b}$ Department of Micro- and Nanotechnology, Technical University of Denmark, Ørsteds Plads, Building 345 East, 2800 Kgs. Lyngby, Denmark;

*Corresponding author. Tel.: +45 452516 21; e-mail address: asfj@env.dtu.dk

\section{Acknowledgements}

This work was funded by the joint Korea Advanced Institute of Science \& Technology and Technical University of Denmark (KAIST-DTU) signature project, INtegrated WAter Technology. We would like to acknowledge B.Sc. Eva Caspersen for her contribution to the laboratory work. 


\section{ABSTRACT}

The stability of gold nanoparticles (AuNPs) stabilized electrostatically with citrate or (electro)sterically by commercially available amphiphilic block copolymers (PVP-VA or PVA-COOH) was studied under various physicochemical conditions. Subsequently, the mobility of the AuNPs in porous media (sand) was investigated in column studies under environmental relevant physicochemical conditions. Electrostatically stabilized AuNPs were unstable under most physicochemical conditions due to the compression of the electrical double layer. Consequently, aggregation and deposition rapidly immobilized the AuNPs. Sterically stabilized AuNPs showed significantly less sensitivity towards changes in the physicochemical conditions with high stability, high mobility with negligible retardation, and particle deposition rate coefficients ranging an order of magnitude $\left(1.5 \times 10^{-3}\right.$ to $1.5 \times 10^{-}$ ${ }^{2} \mathrm{~min}^{-1}$ ) depending on the type and amount of stabilizer, and thereby the surface coverage and attachment affinity. The transport of sterically stabilized AuNPs is facilitated by reversible deposition in shallow energy minima with continuous reentrainment and blocking of available attachment sites by deposited AuNPs. The stability and mobility of NPs in the environment will thereby be highly dependent on the specific stabilizing agent and variations in the coverage on the NP. Under the given experimental conditions, transport distances of the most mobile AuNPs of up to $20 \mathrm{~m}$ is expected. Due to their size specific plasmonic properties, the easily detectable AuNPs are proposed as potential model or tracer particles for studying transport of various stabilized NPs under environmental conditions.

Keywords: Gold nanoparticles; model nanoparticles; citrate; amphiphilic block copolymers; stability; mobility

\section{Introduction}

Nanomaterials are manufactured for their specific nanosize related properties, which provides possibilities for new and improved products and applications. The increased application of engineered 
nanoparticles (ENPs) in everyday products such as cosmetics, textiles, paints, plastics and electronics will inevitable result in their appearance in waste streams (e.g. wastewater, sludge, landfills) and consequently in the environment (Keller \& Lazareva 2014; Park et al. 2017). The seriousness of potential impacts on ecosystems is an on-going topic of discussion as some ENP properties are still poorly understood. The limited insights into toxicity, environmental behavior and environmental concentrations of various ENPs (subject to variations in e.g. size, shape, surface areas and functionalization) hinder qualified risk assessment (Gottschalk et al. 2013; Peng et al. 2017; Quik et al. 2011) and more research on especially exposure assessment, including fate and transport, is needed (Baalousha et al. 2016).

In recent years, advances have been made to the basic understanding of mechanisms controlling the transport in simple porous media systems (i.e. deionized water or simple electrolyte solution, homogeneous glass/silica media), where a consensus on the impact from water chemistry (ionic strength, $\mathrm{pH}$, divalent ions) and porous media properties (e.g. grain size) are seen across a number of studied ENPs such as carbon based NPs (Kamrani et al. 2018; Kasel et al. 2013), nZVI (Saleh et al. 2008; Saberinasr et al. 2016), $\mathrm{TiO}_{2}$ NPs (French et al. 2009; Xu et al. 2017) and AgNPs (Park et al. 2016). However, the number of studies with natural waters and/or soils are more limited and show deviations in the NP behavior compared to the more artificial systems (Kumar et al. 2017; Petosa et al. 2013; Sun et al. 2015; Yecheskel et al. 2018). Apart from the media properties, the properties of the ENPs also control the fate and transport. The small sizes and the enhanced surface activity of NPs make them sensitive towards the physical and chemical nature of their surrounding matrix. Normally, suspensions of NPs are not very stable and tend to aggregate, whereby their properties as single particles vanish. However, advancements in surface functionalization using a large variety of natural and synthetic compounds (e.g. polymers) have enhanced their colloidal stability (Schärtl 2010), which may lead to unintended impacts, such as enhancing the risk of spreading in the environment. The type of surface coating is a key parameter governing the mobility of NPs; different types will behave 
differently under the same condition (Yang et al. 2018). Not only the coating attached to the ENPs, but also any excess coating or natural organic matter (NOM) in solution can facilitate the transport (Becker et al. 2015; Johnson et al. 2009; Kim et al. 2015). While the impact on transport from variation in concentration of NOM has been the focus of several studies (Franchi \& O’Melia 2003; Hwang et al. 2018; Johnson et al. 2009; Kim et al 2015; Park et al 2016; Yang et al. 2018), the impact from variations in concentration and coverage of different synthetic coatings is less studied. Ligand exchange is a common procedure for functionalization of NPs, where one NP surface ligand is replaced with another through complex, multiple bond-breaking pathways (Sardar et al. 2009). Because of this, ligand exchange may also occur between the functionalized NPs and ligands on the porous media (e.g. hydroxylated mineral surfaces) during transport.

The limited knowledge on subsurface fate and transport can be related to the difficulties in measuring ENPs in complex environmental samples e.g. detection against a background of naturally occurring colloids or after transformation processes that the functionalized ENPs may undergo in the subsurface (Baalousha et al. 2016; Montaño et al. 2014; von der Kammer et al. 2012). To overcome some of these challenges gold nanoparticles (AuNPs) may be of interest. AuNPs are predicted to be key building blocks and materials in the $21^{\text {st }}$ century due to their unique optical-electrical properties, high stability as an inert noble metal, diverse functionalization and perceived biocompatibility, which allow an extraordinary variety of applications within the fields of biology, medicine, chemistry and physics (Anker et al. 2008; Daniel \& Astruc 2004). The unique properties of AuNPs also make them the model system of choice for exploring a wide range of phenomena related to metal NPs (Sardar et al. 2009). The intense plasmonic properties of AuNPs enables detection of low concentrations (ug $\mathrm{L}^{-1}$ ) by nondestructive analysis using simple spectrophotometric methods (Zuber et al. 2016) suitable for routine monitoring of NPs. The localized surface plasmon resonance (LSPR) of AuNPs depend on their size and shape, which can be exploited for observation of transformations processes resulting in aggregation (Haiss et al. 2007; Jain et al. 2006). AuNPs has in recent environmental fate research been used as 
model NPs to study the aggregation of ENPs in aquatic systems (Smith et al. 2015; Surette \& Nason 2016) and the adhesion to soils rich on natural organic material (El Hadri et al. 2018). The mentioned AuNPs characteristics, and the rare chances of natural occurrence, suggest the possibility of also using AuNPs as model or tracer NPs for other kinds of (metal) NPs in the subsurface. The use of AuNPs as model NPs relies on the assumption that other NPs with the same size, shape and coating would behave in a similar way. At full surface coverage, the coating is the component in direct interaction with the media, but for some NPs (e.g. magnetic NPs) the properties of the core will still be of importance.

The scope of this paper is to investigate the stability and mobility of AuNPs functionalized by electrostatic and (electro)steric stabilizers under environmental relevant physicochemical conditions (aerated and sand filtered groundwater) in a homogeneous quartz sand medium, thereby adding to the understanding of NP behavior in more natural waters. The chosen stabilizers are citrate and two amphiphilic block copolymers i.e. nonionic poly(vinyl pyrrolidone-co-vinyl acetate), hereafter PVPVA, and anionic poly(vinyl alcohol-co-vinyl acetate) containing carboxylic groups, hereafter PVA$\mathrm{COOH}$. The amphiphilic block copolymers differs in their attachment to the AuNP surfaces, where PVP (of PVP-VA) is considered better anchored to the gold surfaces though coordinate covalent bonds with the nitrogen or the carbonyl oxygen (Koczkur et al. 2015) compared to the anchoring though available carboxyl groups (of PVA-COOH) (Hurtado et al. 2017). PVA-COOH is thereby expected to be more easily lost through ligand exchange with the porous media. The stability under various physicochemical conditions was studied by observations of the changes in the UltraViolet-Visible (UVVis) absorption spectra, while the mobility was investigated in column studies with saturated porous media (sand).

\section{Materials and methods}

\section{Materials}


Gold (III) chloride hydrate, sodium hydroxide, and trisodium citrate dihydrate were purchased from Sigma-Aldrich Corporation (St. Louis, MO, USA). Anionic, carboxylic acid modified PVA (PVA$\mathrm{COOH}$ ), with a viscosity of 20-30 mPa s, a degree of hydrolysis of 85-90\% and a molar weight around $100000 \mathrm{~g} \mathrm{~mol}^{-1}$, was kindly supplied by Kuraray Europe Nordic AB OY, Vantaa, Finland. Nonionic PVP-VA, with a viscosity of 26-34 mPa s and a molar weight around $65000 \mathrm{~g} \mathrm{~mol}^{-1}$, was kindly supplied by BASF A/S, Copenhagen, Denmark. The polymers in solution were slightly acidic.

Tap water was used as a representative for groundwater, as tap water in Denmark consists of groundwater, which has undergone minimal treatments i.e. aeration and sand filtration (iron and manganese removal). The main ionic species in the tap water are bicarbonate (320 $\left.\mathrm{mg} \mathrm{L}^{-1}\right)$, calcium (110 mg L $\left.{ }^{-1}\right)$, chloride (85 mg L $\left.{ }^{-1}\right)$, sulfate $\left(45 \mathrm{mg} \mathrm{L}^{-1}\right)$, sodium (35 mg L $\left.{ }^{-1}\right)$, magnesium $\left(15 \mathrm{mg} \mathrm{L}^{-1}\right)$, potassium $\left(5 \mathrm{mg} \mathrm{L}^{-1}\right)$ and nitrate $\left(1 \mathrm{mg} \mathrm{L}^{-1}\right)$. The tap water has a $\mathrm{pH}$ of 7.7. All experiments were run at room temperature.

\section{Synthesis and stabilization of AuNPs}

Spherical AuNPs with a high particle concentration (500 $\left.\mathrm{mg} \mathrm{L}^{-1}\right)$ and a low size-distribution were synthesized by the citrate reduction method in the presence of sodium hydroxide (NaOH) as described by Li et al. (2011). High gold concentrations were preferred to ensure measurable effluent gold concentrations in the column mobility studies, while injecting a limited volume pulse to reduce the NP mass loading ( $\mathrm{mg} \mathrm{kg}^{-1}$ sand).

In details, $30 \mathrm{~mL}$ of $5 \mathrm{mM}$ chloroauric acid, $15 \mathrm{~mL}$ of $25 \mathrm{mM} \mathrm{NaOH}$ and $6 \mathrm{~mL}$ of Milli Q${ }^{\circledR}$ water were added to a $100 \mathrm{~mL}$ round bottom flask fitted with a water condenser and kept in an oil bath at $110^{\circ} \mathrm{C}$ until boiling. While boiling, $9 \mathrm{~mL}$ of slightly warmed $1 \%(\mathrm{w} / \mathrm{v})$ sodium citrate solution was added rapidly under vigorous stirring. On the appearance of a dark wine red color, the solution was boiled for 15 minutes and then cooled to room temperature. The above synthesized AuNPs were stabilized (post-grafting) with the amphiphilic block copolymer by adding $10 \mathrm{mg} \mathrm{mL}^{-1}$ solutions of 
PVA-COOH or PVP-VA at room temperature and shaking for 6 hours. The particle to polymer concentration ratio between AuNPs and polymers were kept as 1:1 or 1:10 (w/w).

\section{Stability test}

The stability of citrate and amphiphilic block copolymer stabilized AuNPs (1:1) were studied upon contact with different media (various ionic strength and $\mathrm{pH}$ ) by recording the UV-Vis absorption spectra from 400 to 800 nm within an hour after mixing (Chan \& Vikesland 2014; Li et al. 2011; Zhou et al. 2009). $2 \mathrm{~mL}$ of each AuNP suspensions were mixed with $2 \mathrm{~mL}$ of different media i.e. Milli Q water, tap water (pH 7.7 and ionic strength $0.012 \mathrm{M}$ ), $\mathrm{NaCl}$ solutions (ionic strength 0.2-0.9 M, neutral $\mathrm{pH}$ ), and $\mathrm{KCl}$ buffer solutions adjusted with either $\mathrm{HCl}$ or $\mathrm{NaOH}$ for different $\mathrm{pH}$ (ionic strength $0.2 \mathrm{M}$;

$\mathrm{pH}$ 2-12). Each spectrum was normalized with respect to the absorption maximum and then plotted against the wavelengths for comparison. In addition, the stability of PVA-COOH stabilized AuNPs $(1: 10)$ in tap water was also tested.

\section{Mobility tests}

The mobility of the AuNPs was determined by column experiments. The columns were made of transparent PVC with a length of $30 \mathrm{~cm}$ (2.25 cm ID) and connected with PA11 nylon tubing (2 mm ID) to a peristaltic pump. The columns were packed with washed and sorted fine filter sand (Dansand A/S, Denmark, EN 12904:2005) consisting primarily of silica (98.7\%) with small fractions of $\mathrm{Al}_{2} \mathrm{O}_{3}$ (0.64 \%), $\mathrm{K}_{2} \mathrm{O}(0.44 \%), \mathrm{Fe}_{2} \mathrm{O}_{3}(0.06 \%), \mathrm{Na}_{2} \mathrm{O}(0.06 \%)$ and $\mathrm{CaO}(0.03 \%)$. The sand had a mean size of $0.53 \mathrm{~mm}(0.32-0.71 \mathrm{~mm})$. Packing was done by tamping several times (approximately every $2 \mathrm{~mL}$ ) to ensure a dense and even sand distribution in the columns. The resulting porosity was approximately $0.42 \pm 0.01$ (based on fitting of the tracer tests). The column in- and outlet were protected by cellulose membrane filters $(0.46 \mu \mathrm{m})$, which after the experiments were visually inspected for any red coloration to access AuNPs filtration (no coloration was observed). The columns were flushed by $\mathrm{CO}_{2}$ for a minimum of 2 hours (to prevent air entrapment) followed by deionized water (20 PV) before introduction of the tracer and tap water (20 PV) before the introduction of AuNPs. The tracer and 
AuNPs experiments were done with a flow (upwards) of $1.0 \mathrm{~mL} \mathrm{~min} \mathrm{~m}^{-1}$ equal to a Darcy velocity of approximately $1300 \mathrm{~m} \mathrm{yr}^{-1}$.

Initially, a non-reactive chloride tracer solution was introduced to the columns to determine the flow characteristics in the porous media as a base for comparison with the AuNP suspensions. $12 \mathrm{~mL}(0.2$ pore volumes, PV) of a $500 \mathrm{mg} \mathrm{L}^{-1}$ chloride solution $(\mathrm{NaCl})$ was added to the columns followed by water. Effluent samples were collected continuously every 4 min and the chloride concentration was determined by chloride titration (Hach Lange, Titralab TIM865). The columns were flushed with tap water after the tracer experiments to remove excess chloride tracer.

The AuNP suspensions tested were: citrate stabilized AuNPs; PVA-COOH stabilized AuNPs with particle to polymer ratios of 1:1 and 1:10 (w/w); and PVP-VA stabilized AuNPs with particle to polymer ratios of $1: 1$ and 1:10 (w/w). The suspension with PVA-COOH stabilized AuNPs (1:1) was also tested in a column without prior introduction of the tracer. The two columns (with and without prior tracer addition) gave very comparable AuNP breakthrough curves regarding both shape and recovery indicating no significant impact on the particle behavior in the column from any residual chloride tracer after flushing.

After establishing a continuous flow with tap water, $12 \mathrm{~mL}(0.2 \mathrm{PV})$ of each of the five AuNPs suspensions (500 $\mathrm{mg} \mathrm{L}^{-1}$; $30 \mathrm{mg} \mathrm{kg}^{-1}$ ) were added to each their column followed by tap water. Effluent samples were collected every 4-8 min for approximately 2 PV (100 min) and the AuNP concentrations were determined.

Smaller glass columns (12 cm long, $1.2 \mathrm{~cm}$ ID) were used to test the breakthrough behavior of selected AuNP suspensions (PVA-COOH 1:10 and PVP-VA 1:10) of a longer injection duration (plateau behavior). The columns were flushed by tap water before the addition of $20 \mathrm{~mL}$ (3.7 PV) AuNP suspension (500 mg L-1; $450 \mathrm{mg} \mathrm{kg}^{-1}$ ), which was followed by tap water. Effluent samples were collected approximately every 0.3 PV for around 6 PV and the AuNP concentrations determined.

\section{Characterization and Instrumentation}


The AuNPs were characterized with regard to the size distribution by Transmission Electron Microscopy (TEM) images (Tecnai T20 G2 microscope at $200 \mathrm{kV}$ ) and dynamic light scattering (DLS) using a Malvern Zetasizer Nano series (MA, USA) with $1 \mathrm{~mL}$ sample in the cuvette. The Zetasizer was also used to determine the zeta potential (triplicate) in disposable folded capillary zeta cells (DTS1060C) with an electric field. The zeta potential and the hydrodynamic diameter was only measured in freshly synthesized AuNPs suspensions (diluted with MilliQ water) not in all the different media. The measurements are used to calculate representative DLVO interaction energy profiles to explain overall trends rather than get specific profiles for all media; an assessment of the importance of using representative data is given in the Supplementary Material.

The optical absorption spectra of different suspensions of AuNPs were recorded using a Shimadzu UV-Vis spectrophotometer (1800 model). To determine the AuNP concentration the absorbance was measured at $521 \mathrm{~nm}$. A standard curve was produced (8 standards) with an $\mathrm{r}^{2}>0.999$. For detection of low concentrations (ppb level) of AuNPs a Liquid Waveguide Capillary Cell (LWCC) from World Precision Instruments (path length $50 \mathrm{~cm}$ ) was connected via optical fiber cables to the UV-Vis spectrophotometer (Lee et al. 2017). Twofold dilution series of PVP-VA (1:10) stabilized AuNP suspension (initial $1 \mathrm{mg} \mathrm{L}^{-1}$ ) were made with tap water to confirm the low concentration detectability and stability of AuNPs as seen for (MilliQ) water by Zuber et al. (2016).

\section{Total interaction energy modelling}

The total interaction energy for the AuNP suspensions based on classical DLVO (Derjaguin-LandauVerwey-Overbeck) theory and extended steric interactions was modelled for representative conditions assuming interactions between same size spheres. The classic DLVO energy is defined as the sum of repulsive electrical double layer and attractive van der Waals interactions (Park \& Kim 2015; Hogg et al. 1966). For small surface potentials ( $<60 \mathrm{mV}$ ) and a separation distance, $\mathrm{h}$, smaller than the particle size, the electrical double layer interaction $\left(\mathrm{V}_{\text {edl }}\right)$ is calculated by: 


$$
V_{e d l}=\pi \varepsilon_{0} \varepsilon a_{p} \psi^{2}\left\{\ln \left[\frac{1+\exp (-\kappa h)}{1-\exp (-\kappa h)}\right]+\ln [1-\exp (-2 \kappa h)]\right\}
$$

where $\varepsilon_{0}$ is the dielectric permittivity of a vacuum, $\varepsilon$ is the relative dielectric permittivity of water, $a_{p}$ is the (hydrodynamic) radius of the particle, $\psi$ is the surface potential of the particle, and $\kappa$ is the inverse Debye length calculated by:

$$
\kappa=\sqrt{\frac{2 N_{A} e^{2} I}{\varepsilon_{0} \varepsilon k_{B} T}}
$$

where $\mathrm{N}_{\mathrm{A}}$ is Avogadro's number, e is the elementary electric charge, I is the ionic strength of the solution, $\mathrm{k}_{\mathrm{B}}$ is Boltzmann's constant and $\mathrm{T}$ is the absolute temperature.

For relatively small potentials, the surface potential of the particle can be estimated based on the zeta potential, $\zeta$, of the particle (van Oss et al. 1990):

$$
\psi=\zeta\left(1+\frac{z}{a_{p}}\right) \exp (\kappa z)
$$

where $\mathrm{z}$ is the distance between the surface of the particle and the slipping plane (typically $5 \AA$ ).

The van der Waals interaction $\left(\mathrm{V}_{\mathrm{vdW}}\right)$ is calculated by:

$$
V_{v d W}=-\frac{A_{12} a_{p}}{12 h}\left(1+\frac{14 h}{\lambda}\right)^{-1}
$$

$\mathrm{A}_{12}$ is the Hamaker constant for the "gold - water - gold" system calculated as $2.2^{-19} \mathrm{~J}$ based on Hamaker constants for each of the two materials (Cao 2004) and $\lambda$ is the characteristic wavelength (assumed $100 \mathrm{~nm}$ ).

The extended steric interactions can be divided in the osmotic and elastic repulsion energies, which are defined in the range of $0<\mathrm{h} \leq \mathrm{d}$, where $\mathrm{d}$ is the layer thickness of the polymer brush (Fritz et al. 2002; Lu 2008; Song et al. 2011), which is estimated based on DLS measurements of the hydrodynamic diameter with and without a polymer brush (cf. Table 1). The osmotic interaction ( $\left.\mathrm{V}_{\text {osm }}\right)$ is calculated by:

$$
V_{o s m}=-\frac{2 \pi a \varphi_{p}^{2} N_{A} k_{B} T}{v}\left(\frac{1}{2}-\chi\right)(d-h)^{2}
$$


where a is the radius of the particle core, $v$ is the molar volume of water, $\chi$ is the Flory-Huggins solvency parameter of the polymer (assumed 0.45 ), and $\varphi_{\mathrm{p}}$ is the volume fraction of the polymer estimated by:

$$
\varphi_{p}=3 \frac{\Gamma a^{2}}{\rho_{p}\left[(d+a)^{3}-a^{3}\right]}
$$

where $\rho_{\mathrm{p}}$ is the polymer density (around $1.3 \mathrm{~g} \mathrm{~cm}^{-3}$ ) and $\Gamma$ is the surface concentration (coverage),

which is estimated to $1.3-5.8 \mathrm{mg} \mathrm{m}^{-2}$ depending on the coating type and the particle to polymer ratio (cf. eq. S1 in the Supplementary Material).

The elastic repulsion interaction $\left(V_{\text {elas }}\right)$ is calculated by:

$$
V_{\text {elas }}=-\frac{2 \pi a \varphi_{p} N_{A} d^{2} \rho_{p} k_{B} T}{M_{w}}\left[\frac{2}{3}-\frac{1}{6}\left(\frac{h}{d}\right)^{3}-\frac{h}{2 d}+\frac{h}{d} \ln \left(\frac{h}{d}\right)\right]
$$

where $\mathrm{M}_{\mathrm{w}}$ is molecular weight of the polymer.

\section{D modelling of transport and deposition}

The transport and deposition of particles in columns with a homogeneous porous media can under saturated flow conditions be described by a mass balance accounting for advection, hydrodynamic dispersion and deposition of the particles, which is expressed as a partial differential equation and solved. This is the approach for nearly all transport models for ENPs, which differ only in the complexity of the deposition mechanisms modelling (Baalousha et al. 2016). Baalousha et al. (2016) question the need for sophisticated backwards models with highly accurate mechanisms based on column studies when extrapolating to field conditions and prediction of NP transport. In this study, a simple analytical approach has been used for data analysis. The concentration of suspended particles $\mathrm{C}(\mathrm{x}, \mathrm{t})$ at a column length $\mathrm{x}$ and time $\mathrm{t}$ was modeled by the following one-dimensional advectiondispersion equation (1D ADE) coupled with a single sink term for the particle deposition (Chen et al. 2001; Grolimund et al. 1998):

$$
\frac{\partial C}{\partial t}=D \frac{\partial^{2} C}{\partial x^{2}}-v \frac{\partial C}{\partial x}-k_{d} C,
$$


where $v$ is the interstitial velocity of the particles, D is the hydrodynamic dispersion coefficient and $k_{d}$ is the particle deposition rate coefficient. This is valid under the assumption that particle deposition is irreversible and occurs with 1.order kinetics.

For a semi-infinite column initially free of particles, the 1D ADE can be solved for a step injection, where $\mathrm{C}(0, \mathrm{t})$ is $\mathrm{C}_{0}$ for the length of the injection $\left(\mathrm{t}_{0}\right)$ and zero at $\mathrm{t}>\mathrm{t}_{0}$, by use of Laplace transformation (van Genuchten 1981):

$$
C(x, t)=\left\{\begin{array}{l}
C_{0} H(x, t) \text { for } 0<t \leq t_{0} \\
C_{0}\left(H(x, t)-H\left(x, t-t_{0}\right)\right) \text { for } t>t_{0}
\end{array}\right.
$$

where $H(x, t)$ is given by:

$$
H(x, t)=\frac{1}{2} \exp \left(\frac{(v-u) x}{2 D}\right) \operatorname{erfc}\left(\frac{R x-u t}{2 \sqrt{D R t}}\right)+\frac{1}{2} \exp \left(\frac{(v+u) x}{2 D}\right) \operatorname{erfc}\left(\frac{R x+u t}{2 \sqrt{D R t}}\right)
$$

and $\mathrm{u}$ is given by:

$$
u=v \sqrt{1+\frac{4 k_{d} D}{v^{2}}}
$$

where $\mathrm{R}$ is the retardation factor and the values for $\mathrm{D}$ and $\mathrm{k}_{\mathrm{d}}$ are determined simultaneously from the direct fit of the observed particle breakthrough curves. D has typically been fixed based on the fitting to the tracer breakthrough curve ( $k_{d}$ is 0). However, Chrysikopoulos \& Katzourakis (2015) found that the dispersion coefficient increased with particle size $(28-5500 \mathrm{~nm})$ and concluded that tracer fitted dispersion coefficients should not be used to analyze particle breakthrough curves. The dispersion coefficients have therefore been fitted for the individual particles breakthrough curves.

The particle deposition rate coefficient, $\mathrm{k}_{\mathrm{d}}$, can also be described as (Tufenkji \& Elimelech 2004):

$$
k_{d}=\frac{3}{2} \frac{(1-\theta)}{d_{c} \theta} U \alpha \eta_{0}=\frac{3}{2} \frac{(1-\theta)}{d_{c} \theta} U \eta,
$$

where $\theta$ is the porosity, $d_{c}$ is the average grain size, $U$ is the Darcy velocity, $\alpha$ is the particle-collector attachment efficiency, $\eta_{0}$ is the single collector contact efficiency and $\eta$ is the actual single collector removal efficiency, which can also be determined experimentally from column (length L) breakthrough curve plateaus by (Elimelech et al. 1995): 


$$
\eta=-\frac{2}{3} \frac{d_{c}}{(1-\theta) L} \ln \left(\frac{C}{C_{0}}\right)
$$

For columns where a plateau is not reached (short pulse injection) and the dispersivity, $\alpha_{\mathrm{L}}$, is small with respect to the travel distance $\left(\mathrm{a}_{\mathrm{L}} / \mathrm{L}<0.01\right)$, $\eta$ can be determined by (Harvey \& Garabedian 1991$)$ :

$$
\eta=-\frac{2}{3} \frac{d_{c}}{(1-\theta) L} \ln (R B)
$$

where RB is the relative breakthrough, which is defined as the ratio of the time-integrated mass of the particles relative to that of the conservative tracer.

The transport of particles from the groundwater to the collector is typically governed by three mechanisms: Brownian diffusion, interception and gravitational sedimentation. For particles dominated by Brownian diffusion (i.e. NPs), the single collector contact efficiency can be estimated by (Tufenkji \& Elimelech 2004):

$$
\eta_{0}=4.04 A_{S}{ }^{1 / 3} N_{P e^{-2 / 3}},
$$

where $A_{S}$ is a porosity-dependent parameter defined as:

$$
A_{S}=\frac{2\left(1-(1-\theta)^{5 / 3}\right)}{2-3(1-\theta)^{1 / 3}+3(1-\theta)^{5 / 3}-2(1-\theta)^{2}},
$$

and $\mathrm{N}_{\mathrm{Pe}}$ is the Peclet number characterizing ratio of advective transport to diffusive transport given by:

$$
N_{P e}=\frac{U d_{c}}{D_{\infty}}
$$

where $\mathrm{D}_{\infty}$ is the diffusion coefficient in an infinite medium given by:

$$
\mathrm{D}_{\infty}=\frac{k_{B} T}{6 \pi \mu a_{p}}
$$

where $\mu$ is the absolute fluid viscocity.

\section{Results and discussion}

Synthesis and characterization of AuNPs 
AuNPs suspensions of high gold concentrations (500 $\left.\mathrm{mg} \mathrm{L}^{-1}\right)$ with minimum polydispersity and great colloidal stability were synthesized. The synthesized AuNPs were found to be spherical with an average diameter of $15.9 \pm 2.7 \mathrm{~nm}$ based on 100 TEM measurements (section shown in Figure 1) and a hydrodynamic diameter, $\mathrm{D}_{\mathrm{h}}$, of $19.2 \pm 0.1 \mathrm{~nm}$ (Table 1) based on DLS measurements. The difference between the particle size (size of metallic core) measured by TEM and the hydrodynamic diameter measured by DLS is due to the solvent layer when the particles are dispersed in a liquid medium (coreshell structure).

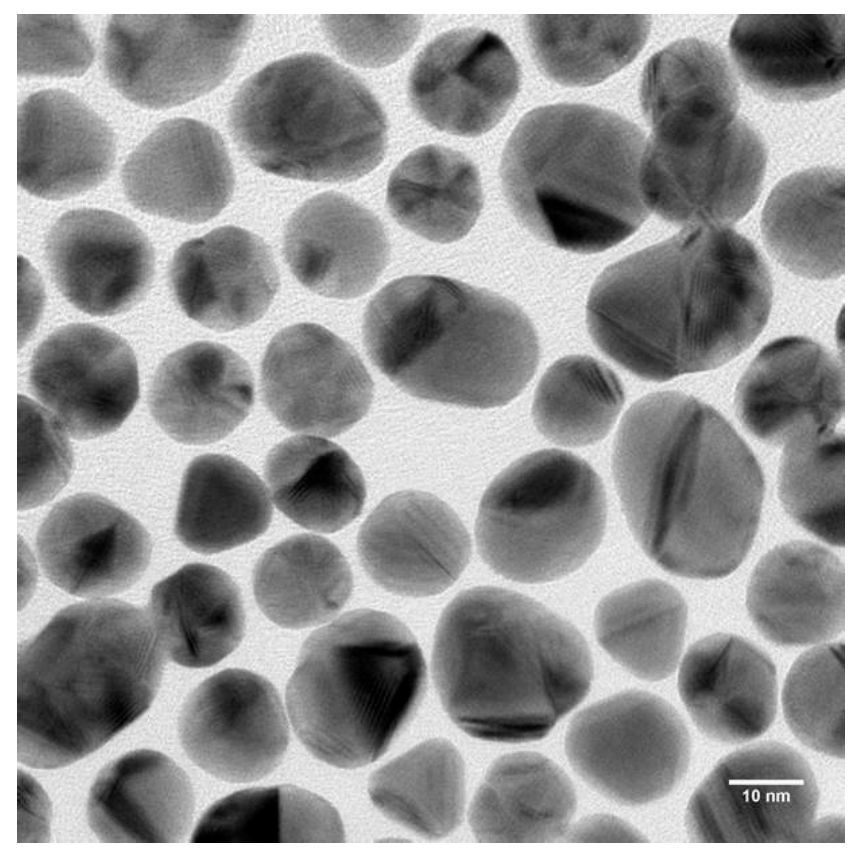

Fig. 1 TEM image of the synthesized spherical AuNPs (citrate stabilized) with an average diameter of $15.9 \pm 2.7 \mathrm{~nm}$ 
Table 1. Hydrodynamic diameter, $d_{h}$, and zeta potential, $\zeta$, of AuNPs stabilized by citrate or amphiphilic block copolymers (PVP-VA or PVA-COOH) measured by DLS. The background solution is MilliQ water (not tap water) and thus represent the synthesized particles before the stability and mobility tests.

\begin{tabular}{lcc}
\hline Species & $\mathbf{d h} \mathbf{( n m})$ & $\zeta(\mathbf{m V})$ \\
\hline Citrate AuNP & $19.2 \pm 0.1$ & $-38.8 \pm 0.1$ \\
AuNP:PVP-VA (1:1) & $23.6 \pm 0.2$ & $-23.6 \pm 1.2$ \\
AuNP:PVP-VA (1:10) & $28.6 \pm 1.7$ & $-13.7 \pm 0.6$ \\
AuNP:PVA-COOH (1:1) & $43.1 \pm 0.1$ & $-11.6 \pm 0.1$ \\
AuNP:PVA-COOH (1:10) & $66.0 \pm 6.7$ & $-5.1 \pm 0.6$ \\
\hline
\end{tabular}

The synthesized AuNPs were all initially electrostatically stabilized with a negative zeta potential (<$30 \mathrm{mV}$ ) resulting from the formation of adlayers of citrate anions adsorbed through central carboxylate groups and/or from ions in solution (Park \& Shumaker-Parry 2014). The post-grafting with the respective polymer solutions (PVP-VA or PVA-COOH) evidently impacts the hydrodynamic diameter and the zeta potential (Table 1). The data on the hydrodynamic diameter reflects the formation of a thicker stabilizing layer with addition of more polymer (1:10 compared to 1:1) and with a bulkier polymer of higher molecular weight (PVA-COOH compared to PVP-VA). The adsorption of the polymers on the AuNPs changes the stabilization mechanism from electrostatic to (electro)steric. In polymers, the chain dimensions are capable of overcoming attractive interaction between particles to stabilize them sterically, which has the advantage of being relatively insensitive to the presence of electrolytes (Louie et al. 2016). With a change in the stabilization mechanism, the increase in the zeta potentials (less negative) of the polymer stabilized AuNPs should not be seen as a reflection of lost overall stability (cf. Figure 2). The zeta potential also reflects adsorption and can be used to evaluate polymer adsorption e.g. the thickness of the polymer layer and the amount of polymer needed to reach the maximum surface concentration (Marchon et al. 2016; Stuart \& Mulder 1985). The increase in zeta 
potential with a change in the particle to polymer ratio from 1:1 to 1:10 indicates an increase in surface coverage.

\section{Stability of AuNPs}

The plasmonic peaks of stabilized AuNPs in various media were measured and compared in the visible region using UV-Vis spectrophotometry (Figure 2). Aggregation of the AuNPs will result in a redshift in the LSPR band. The stability was only tested shortly after mixing ( $1 \mathrm{~h})$ as the subsequent mobility tests were also of short duration (1 PV at $1 \mathrm{~h}$ ). Limited destabilization during the first hours as well as longer term (days-months) has been observed by others for sterically stabilized NPs (e.g. Han et al. 2014; Hwang et al. 2018; Worthen et al. 2016). In the suspensions with MilliQ water, all AuNPs were stable with a plasmonic peak around $518 \mathrm{~nm}$. A small shift in the wavelength for the peak was seen for both PVP-VA stabilized AuNPs (+2.5 nm) and for PVA-COOH stabilized AuNPs (+3.5 nm) compared to citrate stabilized AuNPs.

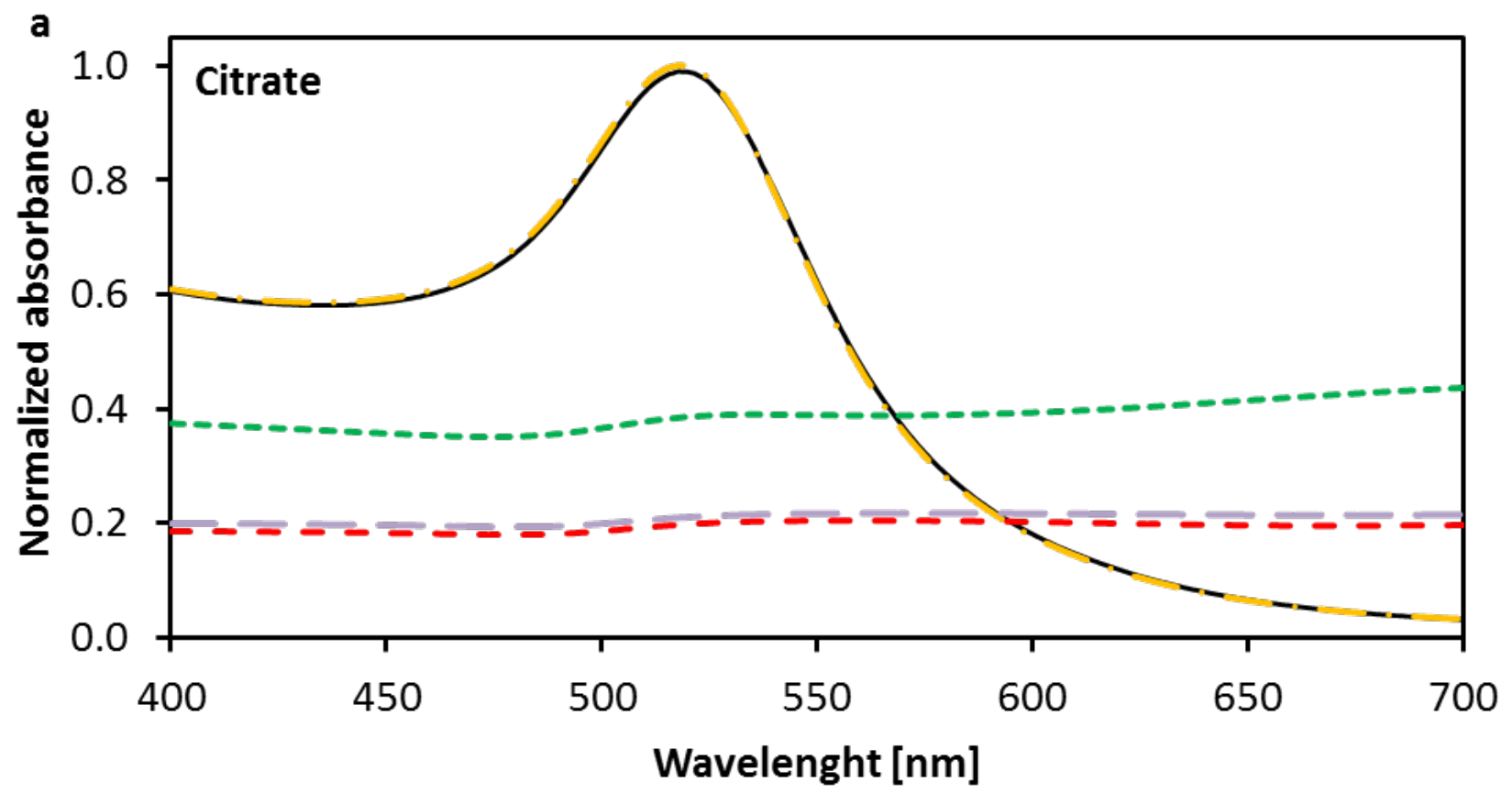



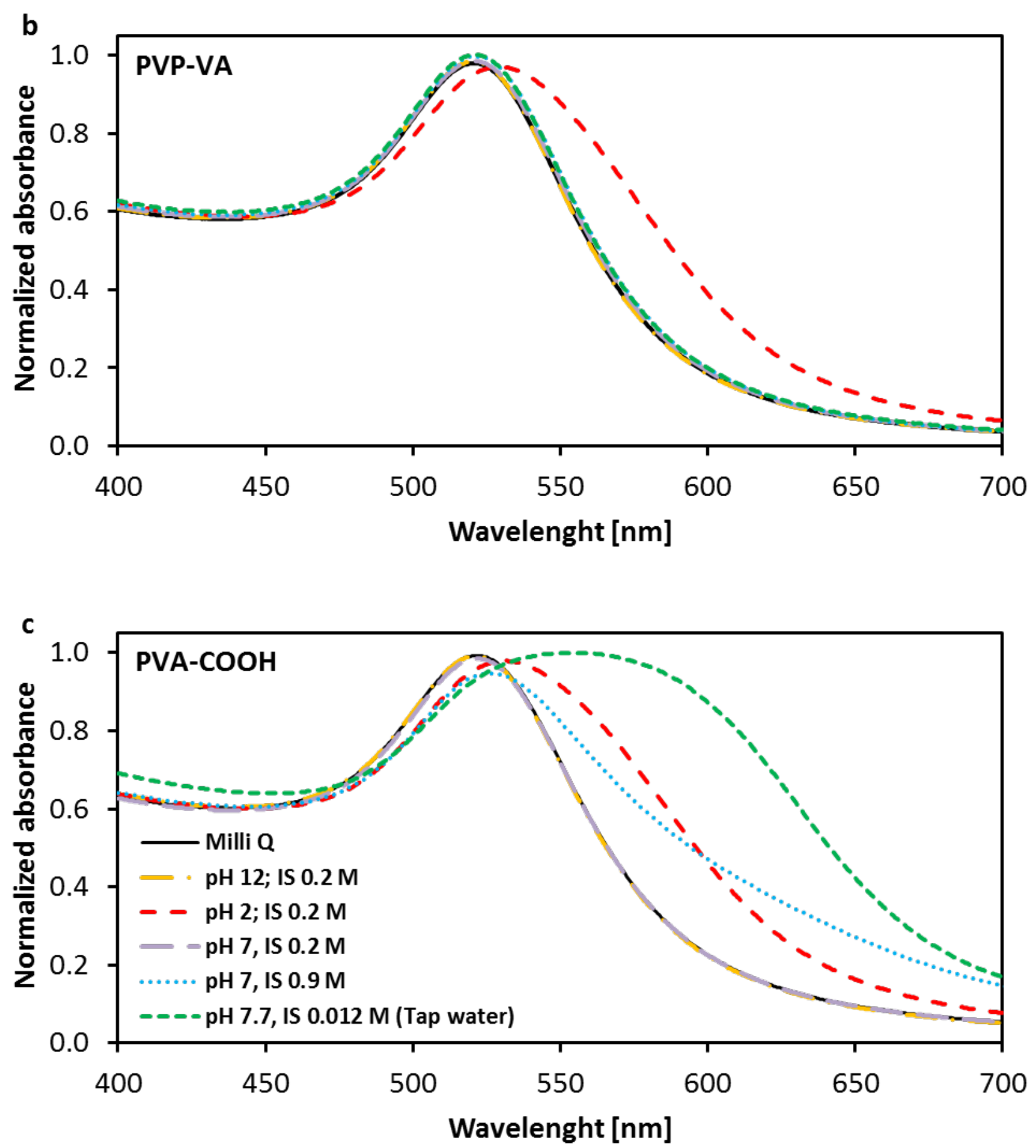

Fig. 2 Stability of AuNPs in various media (different $\mathrm{pH}$ and ionic strength, IS) illustrated by the UV-Vis spectra for: a) citrate stabilized, b) PVP-VA stabilized (1:1), and c) PVA-COOH stabilized (1:1) AuNPs

The citrate stabilized AuNPs were unstable in all the other tested media, except at pH 12 (Figure 2a). High pH situations $\left(\mathrm{OH}^{-}\right)$do not collapse the net negative surface charge of citrate stabilized AuNPs 
and hence retain the electrostatic stability. As the conditions become increasingly acidic, destabilization is expected (Pfeiffer et al. 2014) and also observed. In electrostatic stabilization, electrical double layers form around the particles and the repulsion between these double layers imparts colloidal stability. The thickness of the double layer is a sensitive function of the ionic strength of the medium, where the thickness decreases with increasing ionic strength. At ionic strengths greater than $0.1 \mathrm{M}$ the thickness is less than $1 \mathrm{~nm}$ (Napper 1983). In this situation, electrostatic repulsion is of insufficient range to outweigh the van der Waals attraction between the particles and thus the particles collapse to aggregates as described by classic DLVO theory of colloidal stability. Pamies et al. (2014) observed a significant aggregation at ionic strength above 0.07 $\mathrm{M}$ for small citrate stabilized AuNPs, while the AuNPs were long-term stable at low ionic strengths $(<0.02 \mathrm{M})$. Under relatively neutral $\mathrm{pH}$, the citrate stabilized AuNPs prepared in our study aggregated even under the low ionic strength of the tap water (Figure 2a). Classic DLVO calculations with the measured zeta potential for citrate AuNPs (in MilliQ water) show, that the whole interaction energy profile would become negative already at an ionic strength of 0.009 M. For higher zeta potentials (resulting from interaction with the media) the destabilization would occur at even lower ionic strengths. The calculations show that the interaction energy profile is negative for all the AuNPs at an ionic strength of 0.012 , whereby they are not predicted to be electrostatically stable in the tap water (Figure 3a). 

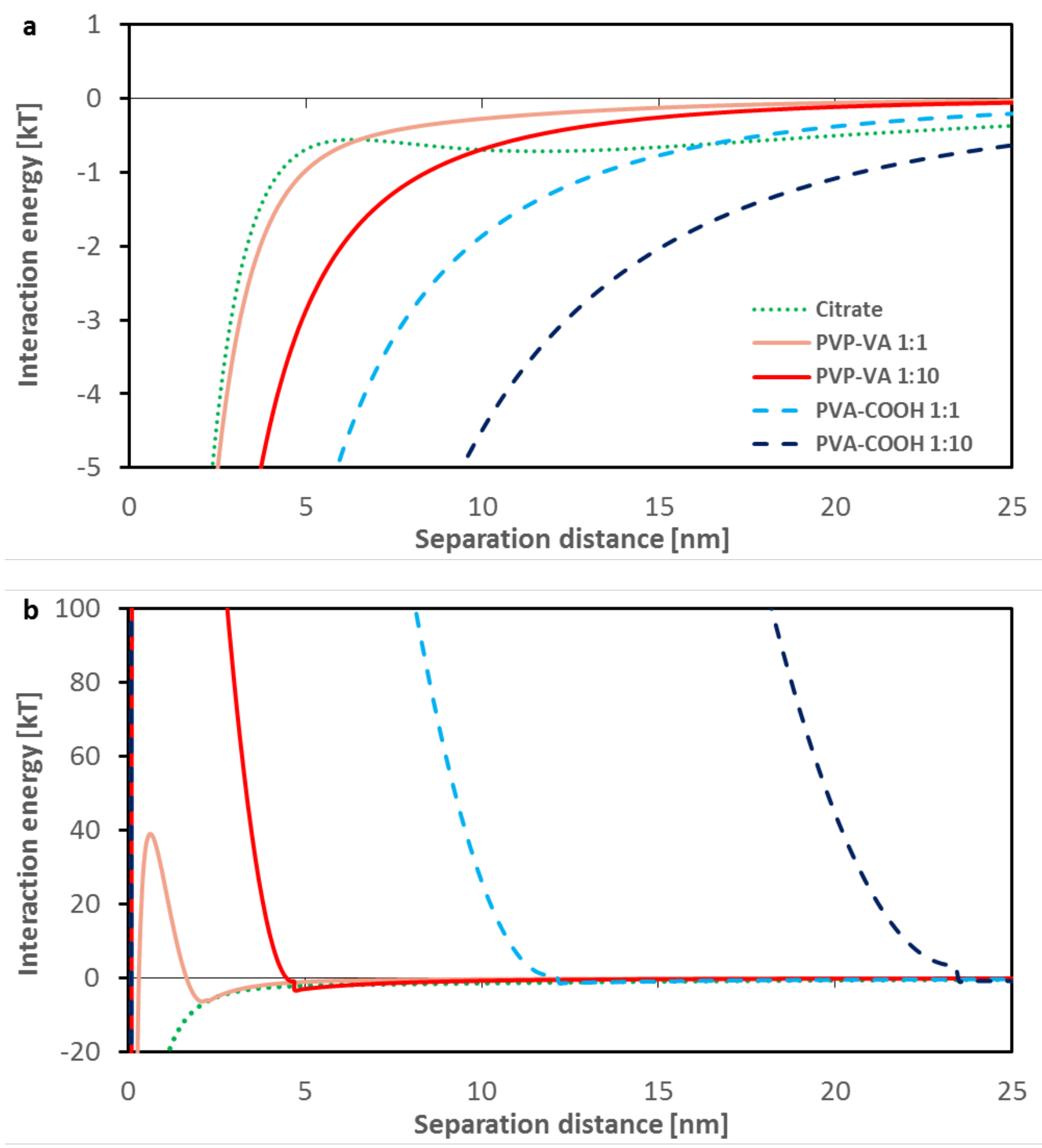

Fig. 3 Total interaction energy (divided by $k_{B} T$ ) as a function of the separation distance for a) classic DLVO $\left(V_{\text {edl }}+V_{v d w}\right)$ using the particle size and zeta potential of all the tested AuNPs (Table 1) and the ionic strength of tap water (0.012 M); and b) extended DLVO also including steric repulsion $\left(\mathrm{V}_{\text {osm }}+\mathrm{V}_{\text {elas }}\right)$. 
In general, amphiphilic block copolymers are considered among the most efficient steric stabilizers (Tadros et al. 2007). The amphiphilic block copolymer stabilized AuNPs are much more stable than the citrate stabilized AuNPs as a result of additional steric repulsion (extended DLVO, Figure 3b). The extent of the steric repulsion depend on the specific polymer and e.g. the surface concentration and the thickness of the stabilizing polymer layer on the NP (Fritz et al. 2002; Napper 1983; Worthen et al. 2016). High energy barriers (40-1800kT) and shallow secondary minima (-1kT to $-6 \mathrm{kT})$ were found for the tap water system (assuming no chance in the polymer layer thickness), and more so for the AuNPs stabilized with PVA-COOH than PVP-VA. The amphiphilic block copolymer stabilized AuNPs are thereby predicted to be sterically stabilized in tap water.

PVP-VA stabilized AuNPs showed extreme stability in different media (Figure 2b) i.e. tap water, ionic strengths up to $0.9 \mathrm{M}$ and neutral to alkaline $\mathrm{pH}$. Only a slight red shift (530 nm, $\mathrm{D}_{\mathrm{h}} 40 \mathrm{~nm}$ ) was observed at strongly acidic conditions. Likewise, PVA-COOH stabilized AuNPs (Figure 2c) showed good stability in neutral to alkaline $\mathrm{pH}$ with a similar slight red shift (530 nm, $\mathrm{D}_{\mathrm{h}} 40 \mathrm{~nm}$ ) at strongly acidic condition. Fritz et al. (2002) found a pH dependency of steric stabilization (nanoplastic) due to protonation of the stabilizing layer at low $\mathrm{pH}$, which resulted in the stabilizing layer collapsing and particle destabilization at increased ionic strengths. The observed destabilization may thereby be the result of protonation of groups in the copolymer layer.

PVA-COOH stabilized AuNPs showed a higher sensitivity towards ionic strength compared to PVPVA. PVA-COOH stabilized AuNPs were stable at an ionic strength of $0.2 \mathrm{M}$, while a slight red shift (527 nm, $D_{h} 30 \mathrm{~nm}$ ) was observed at an ionic strength of $0.9 \mathrm{M}$. The greatest impact on stability was seen in tap water (red shift to $555 \mathrm{~nm}, \mathrm{D}_{\mathrm{h}} 80 \mathrm{~nm}$ ), where a significant broadening of the peak was also observed as a sign of increased polydispersity (Pamies et al. 2014). This stresses the importance of using natural waters.

The higher sensitivity to tap water is not reflected in the DLVO calculations (Fig. 3), where the ionic strength only impact the electrical double layer interaction $\left(V_{\text {edl }}\right)$. Since $V_{\text {edl }}$ is much smaller than the 
predicted steric interaction energy (more than one order of magnitude) at all applied ionic strengths, the lower stability in tap water must be the result of an impact on the steric forces (e.g. impact on the particle size/structure cf. Fig. 2c). The destabilization in tap water of a low ionic strength is thereby likely the result of the more complex composition of tap water, where the divalent destabilizing cations (calcium and magnesium) are among the main ionic species. Others have observed a stronger NP destabilization with divalent cations than with monovalent cations, which could not be explained by the ionic strength alone (Akaighe et al. 2012; Metin et al. 2011; Pavlin \& Bregar 2012). This has been attributed to the divalent ions ability to behave as bridges between like-charged NPs and to compact the surface polymer resulting in aggregation. The negatively charged carboxylate groups (present in PVA$\mathrm{COOH}$ ) are thereby sensitive to divalent cation bridging in the tap water (Tadros et al. 2007; Worthen et al. 2016; Yao et al. 2014; Zamborini et al. 2000). At an increased polymer ratio (1:10) the PVA$\mathrm{COOH}$ stabilized AuNPs were stable at a higher ionic strength (up to $1.7 \mathrm{M}$ ) and in tap water (data not shown). With increased polymer surface coverage, cation bridging may be mitigated by burying the charged carboxylate of the anchoring group in the polymer layer, thereby making them less available for bridging as observed for other ligands (Worthen et al. 2016). The increase in zeta potential observed with additional polymer (Table 1) may be the result of charge burying in the thicker polymer layer.

\section{Mobility of stabilized AuNPs in sand column}

Based on the observed differences in stability of the three types of AuNPs in tap water, the mobility of the particles is expected to also differ. The mobility was evaluated in tap water saturated porous media by breakthrough curves of injected AuNPs (0.2 PV) and mass balance for AuNP recovery. For the 1:10 particle to polymer ratio, the plateau behavior of the breakthrough curves was also examined (3.7 PV injected).

The tracer showed good recovery and was fitted relatively well with the 1D ADE (Table 2, Figure 4a). Slight tailing was observed and ascribed to minor heterogeneities in the packed sand media (e.g. Bijeljic et al. 2011). As expected, based on the stability testing, the injection of 0.2 PV of citrate 
stabilized AuNPs showed no mobility in the porous media (Table 2, Figure 4a) due to rapid destabilization at contact with tap water at the column inlet (clogging observed).
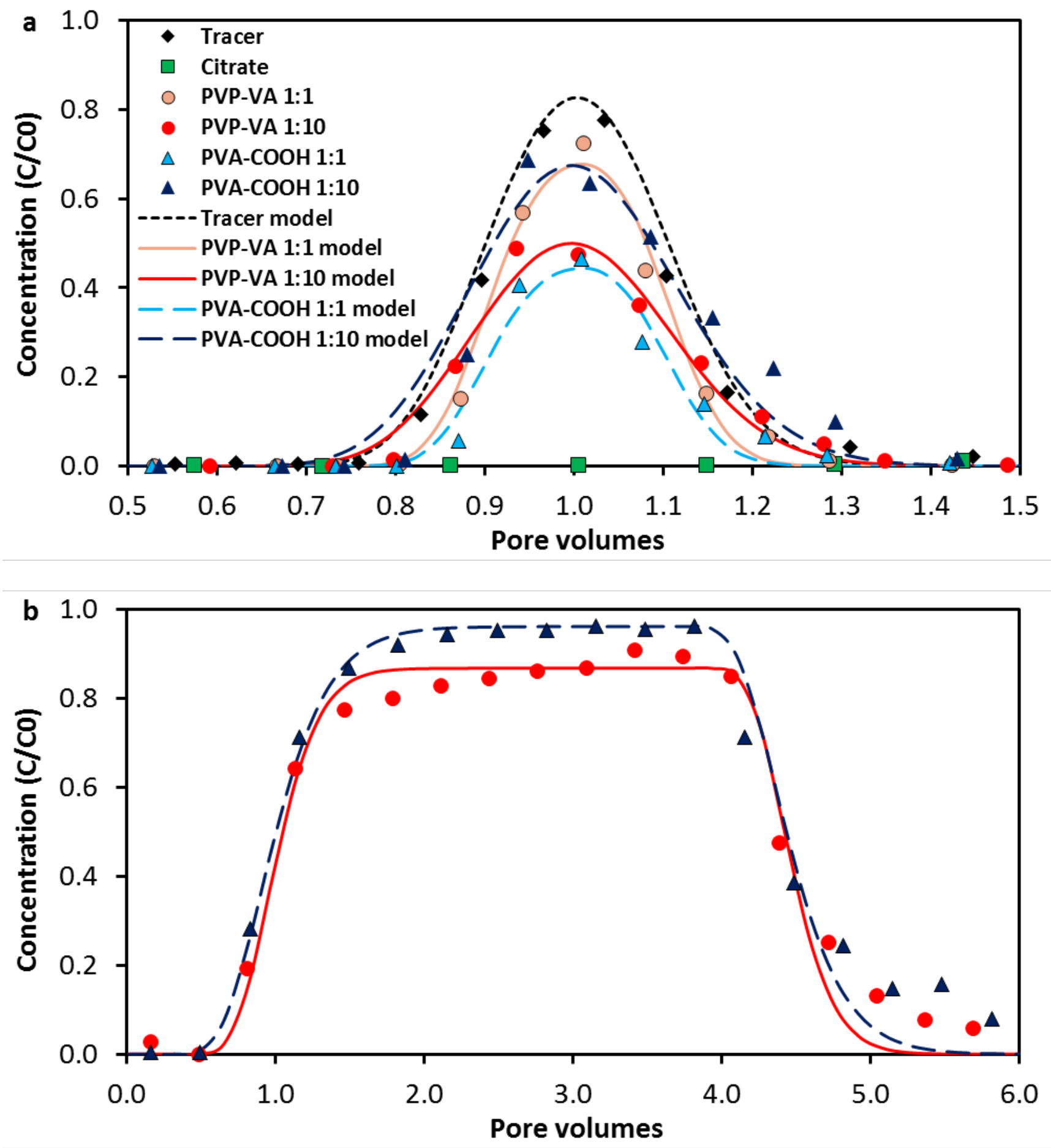

Fig. 4 Breakthrough curves in porous sand media for: a) the tracer (example from the PVP-VA 1:1 column) and the various stabilized AuNPs with injection of $0.2 \mathrm{PV}$, the data is fitted with the 1D ADE model; and b) the amphiphilic block copolymers stabilized AuNP with polymer ratios of 1:10 with injection of 3.7 PV 
Table 2. Breakthrough curve (0.2 PV) characteristics for the tracer (average and standard deviation for the four columns) and the various stabilized AuNPs in tap water saturated porous sand media incl. the experimental breakthrough peak $\left(\mathrm{C}_{\mathrm{C}} \mathrm{C}_{0}\right)$, the recovery of the injected mass in the outlet, the fitted (least square) dispersion coefficient (D) and AuNP deposition rate $\left(k_{d}\right)$ along with the goodness of fit with the 1D ADE $\left(R^{2}\right)$. The calculated particle-collector attachment efficiency $(\alpha)$, single collector contact efficiency $\left(\eta_{0}\right)$, and single collector removal efficiency $(\eta)$ are also included.

\begin{tabular}{lcccccc}
\hline & Tracer & Citrate & PVP-VA & PVP-VA & PVA-COOH & PVA-COOH \\
& & & $1: 1$ & $1: 10$ & $1: 1$ & $1: 10$ \\
\hline Peak $\left(\mathrm{C} / \mathrm{C}_{0}\right)$ & $0.71 \pm 0.05$ & $<0.01$ & 0.73 & 0.49 & 0.46 & 0.69 \\
Recovery (\%) & $97.3 \pm 2.8$ & $\sim 0$ & 72 & 66 & 49 & 95 \\
$\theta$ & $0.42 \pm 0.01$ & 0.42 & 0.44 & 0.42 & 0.42 & 0.41 \\
$\mathrm{D}\left(\mathrm{cm}^{2} \mathrm{~min}^{-1}\right)$ & $7.3 \times 10^{-2} \pm 2.7 \times 10^{-2}$ & - & $2.6 \times 10^{-2}$ & $8.1 \times 10^{-2}$ & $2.4 \times 10^{-2}$ & $9.4 \times 10^{-2}$ \\
$\mathrm{k}_{\mathrm{d}}\left(\mathrm{min}^{-1}\right)$ & - & - & $6.7 \times 10^{-3}$ & $8.1 \times 10^{-3}$ & $14.8 \times 10^{-3}$ & $1.5 \times 10^{-3}$ \\
$\mathrm{R}^{2}$ & $0.96 \pm 0.03$ & - & 0.986 & 0.976 & 0.959 & 0.956 \\
$\eta_{0}$ & - & $12.6 \times 10^{-2}$ & $11.0 \times 10^{-2}$ & $9.7 \times 10^{-2}$ & $7.3 \times 10^{-2}$ & $5.5 \times 10^{-2}$ \\
$\alpha$ & - & - & $6.7 \times 10^{-3}$ & $9.3 \times 10^{-3}$ & $22.2 \times 10^{-3}$ & $3.0 \times 10^{-3}$ \\
$\eta$ & - & - & $7.4 \times 10^{-4}$ & $8.9 \times 10^{-4}$ & $16.3 \times 10^{-4}$ & $1.7 \times 10^{-4}$ \\
\hline
\end{tabular}

All the polymer stabilized AuNPs showed enhanced mobility compared to the citrate AuNPs (Figure 4a). The modelling showed low single collector removal efficiencies (Table 2), which were similar to the ones estimated using the equation (eq. 14) by Harvey \& Garabedian (1991). The lowest recovery and highest deposition rate (Table 2) is found for AuNPs stabilized with PVA-COOH (1:1), which was also the suspension that was found not to be completely stable in tap water (Fig. 2c). Destabilization to some degree in the porous media during the mobility test is therefore also likely.

Early breakthrough of NPs has previously been observed and ascribed to a reduced effective porosity resulting from size/charge exclusion from inner aggregate pore space, preferential flow paths and/or exclusion from the lower-velocity regions (Chrysikopoulos \& Katzourakis 2015; Sagee et al. 2012). In these experiments, the increase in the amount of polymer (increased $d_{h}$ ) had negligible impact on the timing of the breakthrough (Figure 4a). The increase in dispersion with increasing particle size and compared to the tracer, which has been observed for others colloids (e.g. Chrysikopoulos \& Katzourakis 2015), was not observed for the modelled NPs. Only minor variations in the dispersion 
coefficients were found when fitting the dispersion coefficient to the tracer compared to the individual NPs breakthrough curves.

The increased amount of polymer resulted in increased tailing (Figure 4a), which is especially clear for the AuNPs stabilized with PVA-COOH (1:10). The tailing is not captured by fitting the 1D ADE to the experimental data, resulting in a lower goodness of fit (Table 2). Tailing can be explained by particles being reversibly retained in a shallow secondary minimum (Molnar et al. 2015), whereby the 1.order irreversible deposition assumption (eq. 8) is not fulfilled. Li et al. (2017) found that particles subject to classic DLVO interaction forces are preferentially immobilized on irreversible sites (deeper primary minimum) and then occupy reversible sites (shallower secondary minimum) with continued loading. Particles with a larger energy barrier are less likely to be deposited in the primary minimum and more likely to reside in a secondary minimum from where they may be continuously released (Franchi \& O’Melia 2004; Hahn et al. 2004). For particles subject to extended DLVO interaction forces (steric stabilization) the depth of the minimum decreases with an increase in the thickness of the adsorbed polymer layer (Tadros et al. 2007). The effect of the thickness of the polymer layer on the secondary minimum can be seen in Figure 3b; the AuNPs with the thinnest layer (2.2 nm) has a secondary minimum of -6 kT (PVP-VA 1:1), while the AuNPs with the thickest layer (23.4 nm) has a secondary minimum of only -0.7 kT (PVA-COOH 1:10) and in addition a higher energy barrier. The observed tailing behavior is thereby likely due to the deposition and easier reentrainment from the shallow secondary minimum by the AuNPs with a thicker polymer layer and high energy barrier. This fits with most tailing being observed for PVA-COOH (1:10) stabilized AuNPs. The reentrainment of particles may also contribute to the high recovery observed specifically for the AuNPs stabilized with PVA-COOH (1:10), which is comparable to the chloride tracer (Table 2).

For PVP-VA stabilized AuNPs both the mass recovery (66-72 \%) and the deposition rates (7×10-3 $8 \times 10^{-3} \mathrm{~min}^{-1}$ ) are comparable for both the particle to polymer ratios (Table 2 ). The stability tests showed extreme stability already at the lowest particle to polymer ratio (Figure 2a), whereby the 
benefit of additional polymer appear negligible. The particle to polymer ratio have a much bigger impact for PVA-COOH stabilized AuNPs, where PVA-COOH (1:10) shows the overall lowest deposition rate, which is an order of magnitude lower than for PVP-COOH (1:1). This is likely linked with the observed destabilization in tap water for the low particle to polymer ratio, which can occur simultaneous with the transport.

Apart from the differences in stability, the difference in deposition and recovery in the porous media may also be linked to differences in the polymer attachment affinity to the AuNP surfaces and thereby the likelihood of ligand exchange with the porous media. The initial surface coverage with the polymer will be of importance; if too much polymer is lost through ligand exchange, the remaining surface coverage on the AuNPs may not be sufficient to retain stability. This will especially be the case for polymers with weaker attachment to the AuNPs and a lower initial surface coverage. The higher deposition seen for AuNPs stabilized with PVA-COOH (1:1) may thereby partly be caused by enhanced aggregation as the relatively easily exchangeable polymer is loss to the media.

The high mobility of AuNPs stabilized with high polymer concentrations was also reflected in the longer duration (3.7 PV) injections (Figure 4b). The model could be fitted relatively well to the data $\left(\mathrm{R}^{2}=0.97-0.98\right)$, but like for the short duration columns, the tailing is not captured by fitting the $1 \mathrm{D}$ ADE (no detachment term included), and specifically for the PVP-VA stabilized AuNPs the rising plateau could not be fitted (no blocking term included). The mobility of AuNPs stabilized with PVACOOH (1:10) was better than for PVP-VA (1:10) as expected based on the short duration injection (Table 2). The PVA-COOH stabilized AuNPs rapidly reached a plateau ( $\mathrm{C} / \mathrm{C}_{0}$ of 0.96$)$ and both the mass recovery (97\%) and the single collector removal efficiency $\left(2.0 \times 10^{-4}\right)$ were comparable to the short duration injections. This indicates similar transport mechanisms for both the shorter duration injection in the larger columns (lower AuNP load to the porous media of around $30 \mathrm{mg} \mathrm{kg}^{-1}$ ) and the longer duration injection in the smaller columns (higher AuNP load of around $450 \mathrm{mg} \mathrm{kg}{ }^{-1}$ ). The PVPVA stabilized AuNPs also showed good recovery (90 \%), which was better than the short duration 
injection and the calculated single collector removal efficiency was also slightly lower $\left(5.1 \times 10^{-4}\right)$. PVPVA stabilized AuNPs displayed a slightly positive slope of the plateau (until $\mathrm{C} / \mathrm{C}_{0}$ is 0.91 ), which indicates some degree of AuNP deposition blocking by particles already deposited at the porous media. Enhanced blocking of deposition sites at higher injection concentrations has been observed for other NPs (Kasel et al. 2013). The extent of blocking is therefore also expected to be higher in the longer duration injections with a higher AuNP load, which might explain the lower recovery of AuNPs ( $70 \%)$ in the shorter duration injections with the lower AuNP load. Given the higher stability of PVPVA stabilized AuNPs, the mobility may surpass that of PVA-COOH stabilized AuNPs at increased loadings given a larger impact from blocking.

Under the given experimental condition, the AuNPs are immobile when electrostatically stabilized, while the amphiphilic block copolymers facilitates transport distances (99 \% deposition, eq. 13) of up to $20 \mathrm{~m}$ for the most mobile AuNPs. However, the mobility will also depend on the hydraulic properties (e.g. groundwater velocity) and porous media properties (e.g. grain shape and composition). The strong dependency of stability and mobility on the physicochemical conditions (e.g. pH, ionic strength and cations) and the specific stabilizers (e.g. stabilization mechanism and blocking) fits with the observed tendencies for other ENPs in simple systems. The direct comparison of AuNPs to other ENPs in the literature is impeded by variations in experimental conditions; however, the similar overall impacting processes support the possibility of the use of a model or co-injected tracer NP, if tailored to mimic the size, shape and surface functionalization of other ENPs.

\section{Conclusions}

The stability and mobility of AuNPs is greatly determined by the stabilizers employed in the synthesis process and thereby the stabilization mechanism. The presence of (divalent) ions in natural water is likely to favor rapid aggregation and deposition of electrostatically stabilized NPs, as observed with citrate stabilized AuNPs under relatively low ionic strengths ( $<0.02 \mathrm{M})$. Additional steric 
stabilization with anionic or nonionic amphiphilic block copolymers demonstrated a decrease in the sensitivity towards changes in the physicochemical parameters, such as $\mathrm{pH}$, ionic strength and the presence of divalent ions. The anionic stabilizer (PVA-COOH) was more sensitive towards especially divalent ions than the nonionic stabilizer (PVP-VA), which is likely due to bridging between cations in the water and anionic groups of the stabilizer. The sensitivity decreased with an increased polymer concentration, which is likely due to the covering of the charged groups in the polymer brush.

Under environmental conditions, electrostatic stabilized AuNPs are expected to be rapidly immobilized due to the compression of the electrostatic double layer, hence representing a low risk of spreading. For (electro)steric stabilized AuNPs, the mobility will depend on the specific type and ratio of the employed stabilizer, and thereby the surface coverage (density and thickness) and attachment affinity. At maximum surface coverage, the stabilization is expected to be predominantly steric, facilitating the transport of the AuNPs. Based on the observed tailing of sterically stabilized AuNPs, the transport is facilitated to some extend by reversible deposition with continuous reentrainment; especially at higher polymer ratios and thicker polymer layers (shallower energy minima). At high loads of AuNPs, the transport can be further facilitated by blocking of available attachment sites by deposited AuNPs as observed for PVP-VA stabilized AuNPs. The facilitation of transport from particle reentrainment and blocking is expected to be greatest close to the source with higher NP loading. The reentrainment can lead to continuous release of stabilized NPs, where the magnitude may change with alterations of the hydrogeochemical conditions. However, the risk of extensive spreading of the stabilized NPs may be limited by a substantial loss of weakly attached polymers through ligand exchange with the porous media at extended distances. The extent of the loss of stabilizers through ligand exchange as well as deposition site blocking at extended residence times and lower AuNPs loads relevant for environmental matrices (ng- $\mu \mathrm{g} \mathrm{kg} \mathrm{kg}^{-1}$ ) needs to be further examined.

\section{References}


Akaighe, N., Depner, S.W., Banerjee, S., Sharma, V.K., Sohn, M. 2012. The effects of monovalent and divalent cations on the stability of silver nanoparticles formed from direct reduction of silver ions by Suwannee River humic acid/natural organic matter. Sci. Total Environ., 441: 277-289.

Anker, J.N., Hall, W.P., Lyandres, O., Shah, N.C., Zhao, J., Van Duyne, R.P. 2008. Biosensing with plasmonic nanosensors. Nat. Mater., 7: 442-453.

Baalousha, M., Cornelis, G., Kuhlbusch, T.A.J., Lynch, I., Nickel, C., Peijnenburg, W., van den Brink, N.W. 2016. Modeling nanomaterial fate and uptake in the environment: current knowledge and future trends. Environ. Sci.: Nano, 3: 323-345.

Becker, M.D., Wang, Y., Pennell, K.D., Abriola, L.M. 2015. A multi-constituent site blocking model for nanoparticle and stabilizing agent transport in porous media. Environ. Sci.: Nano, 2: 155-166.

Bijeljic, B., Rubin, S., Scher, H., Berkowitz, B. 2011. Non-Fickian transport in porous media with bimodal structural heterogeneity. J. Contam. Hydrol. 120-121: 213-221.

Cao, G. 2004. Nanostructures \& Nanomaterials. Synthesis, Properties \& Applications. Imperial College Press, London.

Chan, M.Y., Vikesland, P.J. 2014. Porous Media-Induced Aggregation of Protein-Stabilized Gold Nanoparticles. Environ. Sci. Technol. 48(3): 1532-1540.

Chen, J.Y., Ko, C.-H., Bhattacharjee, S., Elimelech, M. (2001). Role of spatial distribution of porous medium surface charge heterogeneity in colloid transport. Colloid. Surface. A, 191: 3-15.

Chrysikopoulos, C.V., Katzourakis, V.E. 2015. Colloid particle size-dependent dispersivity. Water Resour. Res., 51: 4668-4683.

Daniel, M.C., Astruc, D. 2004. Gold Nanoparticles: Assembly, Supramolecular Chemistry, QuantumSize-Related Properties, and Applications Toward Biology, Catalysis, and Nanotechnology. Chem. Rev., 104: 293-346. 
El Hadri, H., Louie, S.M., Hackley, V.A. (2018). Assessing the interactions of metal nanoparticles in soil and sediment matrices - a quantitative analytical multi-technique approach. Environ. Sci.: Nano, 5: 203-214.

Elimelech, M., Gregory, J., Jia, X., Williams, R.A. 1995. Particle Deposition and Aggregation: Measurement, Modelling and Simulation. Butterworth-Heinemann Ltd. 290-309.

Franchi, A., O’Melia, C.R. 2003. Effects of Natural Organic Matter and Solution Chemistry on the Deposition and Reentrainment of Colloids in Porous Media. Environ. Sci. Technol., 37(6): 1122-1129. French, R.A., Jacobson, A.R., Kim, B., Isley, S.L., Penn, R.L., Baveye, P.C. 2009. Influence of Ionic Strength, pH, and Cation Valence on Aggregation Kinetics of Titanium Dioxide Nanoparticles. Environ. Sci. Technol., 43: 1354-1359.

Fritz, G., Schädler, V., Willenbacher, N., Wagner, N.J. 2002. Electrosteric Stabilization of Colloidal Dispersions. Langmuir, 18(16): 6381-6390.

van Genuchten, M.T. 1981. Analytical Solutions of the One-Dimensional Convective-Dispersive Solute Transport Equation. U.S. Department of Agriculture, Technical Bulletin No. 1661, 151 p.

Gottschalk, F., Sun, T.Y., Nowack, B. 2013. Environmental concentrations of engineered nanomaterials: Review of modeling and analytical studies. Environ. Pollut., 181: 287-300.

Grolimund, D., Elimelech, M., Borkovec, M., Barmettler, K., Kretzschmar, R., Sticher, H. (1998). Transport of in Situ Mobilized Colloidal Particles in Packed Soil Columns. Environ. Sci. Technol., 32(22), 3562-3569.

Hahn, M.W., Abadzic, D., O’Melia, C.R. 2004. Aquasols: On the Role of Secondary Minima. Environ. Sci. Technol., 38(22): 5915-5924.

Haiss, W., Thanh, N.T.K., Aveyard, J., Fernig, D.G. 2007. Determination of Size and Concentration of Gold Nanoparticles from UV-Vis Spectra. Anal. Chem., 79: 4215-4221. 
Han, Y., Kim, D., Hwang, G., Lee, B., Eom, I., Kim, P.J., Tong, M., Kim, H. 2014. Aggregation and dissolution of $\mathrm{ZnO}$ nanoparticles synthesized by different methods: Influence of ionic strength and humic acid. Colloid. Surface. A, 451: 7-15.

Harvey, R.W., Garabedian, S.P. 1991. Use of Colloid Filtration Theory in Modeling Movement of Bacteria through a Contaminated Sandy Aquifer. Environ. Sci. Technol., 25(1): 178-185.

Hogg, R., Healy, T.W., Fuerstekau, D.W. 1966. Mutual Coagulation of Colloidal Dispersions. T. Faraday Soc., 62: 1638-1651.

Hurtado, R.B., Calderon-Ayala, G., Cortez-Valadez, M. Ramírez-Rodríguez, L.P., Flores-Acosta, M. 2017. Green Synthesis of Metallic and Carbon Nanostructures. Nanomechanics, InTech, DOI:10.5772/intechopen.68483.

Hwang, G., Gomez-Flores, A., Bradford, S.A., Choi, S., Jo, E., Kim, S.B., Tong, M., Kim, H. 2018. Analysis of stability behavior of carbon black nanoparticles in ecotoxicological media: Hydrophobic and steric effects. Colloid. Surface. A, 554: 306-316.

Jain, P.K., Lee, K.S., El-Sayed, I.H., El-Sayed, M.A. 2006. Calculated Absorption and Scattering Properties of Gold Nanoparticles of Different Size, Shape, and Composition: Applications in Biological Imaging and Biomedicine. J. Phys. Chem. B, 110: 7238-7248.

Johnson, R.L., Johnson, G.O., Nurmi, J.T., Tratnyek, P.G. 2009. Natural Organic Matter Enhanced Mobility of Nano Zerovalent Iron. Environ. Sci. Technol., 43(14): 5455-5460.

von der Kammer, F., Ferguson, P.L., Holden, P.A., Masion, A., Rogers, K.R., Klaine, S.J., Koelmans, A.A., Horne, N., Unrine, J.M. 2012. Analysis of Engineered Nanamaterials in Complex Matrices (Environment and Biota): General Considerations and Conceptual Case Studies. Environ. Toxicol. Chem., 31(1): 32-49.

Kamrani, S., Rezaei, M., Kord, M., Baalousha, M. 2018. Transport and retention of carbon dots (CDs) in saturated and unsaturated porous media: Role of ionic strength, $\mathrm{pH}$, and collector grain size. Water Res., 133, 338-347. 
Kasel, D., Bradford, S.A., Šimůnek, J., Heggen, M., Vereecken, H., Klumpp, E. 2013. Transport and retention of multi-walled carbon nanotubes in saturated porous media: Effects of input concentration and grain size. Water Res., 47: 933-944.

Keller, A.A., Lazareva, A. 2014. Predicted Releases of Engineered Nanomaterials: From Global to Regional to Local. Environ. Sci. Technol. Lett., 1: 65-70.

Kim, C., Lee, J., Lee, S. 2015. $\mathrm{TiO}_{2}$ nanoparticle sorption to sand in the presence of natural organic matter. Environ. Earth Sci., 73:5585-5591.

Kumar, N., Labille, J., Bossa1, N., Auffan, M., Doumenq, P., Rose, J., Bottero, J.-Y. 2017. Enhanced transportability of zero valent iron nanoparticles in aquifer sediments: surface modifications, reactivity, and particle traveling distances. Environ. Sci. Pollut. Res., 24: 9269-9277.

Lee, J.-Y., Oh, J.Y., Putri, K.Y., Baik, M.H., Yun, J.-I. 2017. Redox behaviors of Fe(II/III) and U(IV/VI) studied in synthetic water and KURT groundwater by potentiometry and spectroscopy. J. Radioanal. Nucl. Chem., 312: 221-231.

Li, C., Li, D., Wan, G., Xu, J., Hou, W. 2011. Facile synthesis of concentrated gold nanoparticles with low size-distribution in water: temperature and pH controls. Nanoscale Res. Lett., 6: 440.

Louie, S.M., Tilton, R.D., Lowry, G.V. 2016. Critical review: impacts of macromolecular coatings on critical physicochemical processes controlling environmental fate of nanomaterials. Environ. Sci.: Nano, 3: 283-310.

Lu, K. 2008. Theoretical analysis of colloidal interaction energy in nanoparticle suspensions. Ceram. Int., 34: 1353-1360.

Marchon, D., Mantellato, S., Eberhardt, A.B., Flatt, R.J. 2016. Adsorption of chemical admixtures. Science and Technology of Concrete Admixtures, 219-256.

Metin, C.O., Lake, L.W., Miranda, C.R., Nguyen, Q.P. 2011. Stability of aqueous silica nanoparticle dispersions. J. Nanopart. Res., 13: 839-850. 
Molnar, I.L., Johnson, W.P., Gerhard, J.I., Willson, C.S., O’Carroll1, D.M. 2015. Predicting colloid transport through saturated porous media: A critical review. Water Resour. Res., 51: 6804-6845.

Montaño, M.D., Lowry, G.V., von der Kammer, F., Blue, J., Ranville, J.F. 2014. Current status and future direction for examining engineered nanoparticles in natural systems. Environ. Chem., 11: 351366.

Napper, D.H., 1983. Polymeric Stabilization of Colloidal Dispersions. Academic Press INC. (London) Ltd.

Neukum, C., Braun, A., Azzam, R. 2014. Transport of engineered silver (Ag) nanoparticles through partially fractured sandstones. J. Contam. Hydrol. 164: 181-192.

van Oss, C.J., Giese, R.F., Costanzo, P.M. 1990. DLVO and non-DLVO interactions in hectorite. Clay Clay Miner., 38(2): 151-159.

Pamies, R., Cifre, J.G.H., Espín, V.F., Collado-González, M., Banõs, F.G.D., de la Torre, J.G. 2014. Aggregation behaviour of gold nanoparticles in saline aqueous media. J. Nanopart. Res., 16:2376.

Park, C.M., Chu, K.H., Her, N., Jang, M., Baalousha, M., Heo, J., Yoon, Y. 2017. Occurrence and Removal of Engineered Nanoparticles in Drinking Water Treatment and Wastewater Treatment Processes. Sep. Purif. Rev., 46: 255-272.

Park, C.M., Heo, Y., Her, N., Chu, K.H., Jang, M., Yoon, Y. 2016. Modeling the effects of surfactant, hardness, and natural organic matter on deposition and mobility of silver nanoparticles in saturated porous media. Water Res., 103, 38-47.

Park, J.-A., Kim, S.-B. 2015. DLVO and XDLVO calculations for bacteriophage MS2 adhesion to iron oxide particles. J. Contam. Hydrol., 181: 131-140.

Park, J.W., Shumaker-Parry, J.S., 2014. Structural study of citrate layers on gold nanoparticles: Role of intermolecular interactions in stabilizing nanoparticles. J. Am. Chem. Soc., 136: 1907-1921.

Pavlin, M., Bregar, V.B. 2012. Stability of Nanoparticle Suspensions in Different Biologically Relevant Media. Dig. J. Nanomater. Bios., 7(4): 1389-1400. 
Peng, C., Zhang, W., Gao, H., Li, Y., Tong, X., Li, K., Zhu, X., Wang, Y., Chen, Y. 2017. Behavior and Potential Impacts of Metal-Based Engineered Nanoparticles in Aquatic Environments. Nanomaterials, 7: 21.

Petosa, A.R., Öhl, C., Rajput, F., Tufenkji, N. 2013. Mobility of nanosized cerium dioxide and polymeric capsules in quartz and loamy sands saturated with model and natural groundwaters. Water Res., 47: 5889-5900.

Pfeiffer, C., Rehbock, C., Hühn, D., Carrillo-Carrion, C., de Aberasturi, D.J., Merk, V., Barcikowski, S., Parak, W.J. 2014. Interaction of colloidal nanoparticles with their local environment: the (ionic) nanoenvironment around nanoparticles is different from bulk and determines the physico-chemical properties of the nanoparticles. J. R. Soc. Interface, 11: 20130931.

Quik, J.T.K., Vonk, J.A., Hansen, S.F., Baun, A., Van De Meent, D. 2011. How to assess exposure of aquatic organisms to manufactured nanoparticles? Environ. Int., 37: 1068-1077.

Saberinasr, A., Rezaei, M., Nakhaei, M., Hosseini, S.M. 2016. Transport of CMC-Stabilized nZVI in Saturated Sand Column: the Effect of Particle Concentration and Soil Grain Size. Water Air Soil Pollut., 227: 394.

Sagee, O., Dror, I., Berkowitz, B. 2012. Transport of silver nanoparticles (AgNPs) in soil. Chemosphere, 88: 670-675.

Saleh, N., Kim, H.-J., Phenrat, P., Matyjaszewski, K., Tilton, R.D., Lowry, G.V. 2008. Ionic Strength and Composition Affect the Mobility of Surface-Modified $\mathrm{Fe}^{0}$ Nanoparticles in Water-Saturated Sand Columns. Environ. Sci. Technol., 42: 3349-3355.

Sardar, R., Funston, A.M., Mulvaney, P., Murray, R.W. 2009. Gold nanoparticles: Past, present, and future. Langmuir, 25: 13840-13851.

Schärtl, W. 2010. Current directions in core-shell nanoparticle design. Nanoscale, 2: 829-843.

Smith, B.M., Pike, D.J., Kelly, M.O., Nason, J.A. 2015. Quantification of Heteroaggregation between Citrate-Stabilized Gold Nanoparticles and Hematite Colloids. Environ. Sci. Technol., 49: 12789-12797. 
Song, J.E., Phenrat, T., Marinakos, S., Xiao, Y., Liu, J., Wiesner, M.R., Tilton, R.D., Lowry, G.V. 2011. Hydrophobic Interactions Increase Attachment of Gum Arabic- and PVP-Coated Ag Nanoparticles to Hydrophobic Surfaces. Environ. Sci. Technol., 45: 5988-5995.

Stuart, M.A.C., Mulder, J.W. 1985. Adsorbed Polymers in Aqueous Media the Relation between Zeta Potential, Layer Thickness and Ionic Strength. Colloid. Surface., 15: 49-55.

Sun, P., Shijirbaatar, A., Fang, J., Owens, G., Lin, D., Zhang, K. 2015. Distinguishable Transport Behavior of Zinc Oxide Nanoparticles in Silica Sand and Soil Columns. Sci. Total Environ., 505: 189198.

Surette, M.C., Nason, J.A. 2016. Effects of surface coating character and interactions with natural organic matter on the colloidal stability of gold nanoparticles. Environ. Sci.: Nano, 3: 1144-1152. Tadros, T.F. 2007. Colloid Stability: The Role of Surface Forces, Part I. Colloids and Interface Science Series, Vol. 1. WILEY-VCH Verlag GmbH \& Co. KGaA, Weinheim.

Tufenkji, N., Elimelech, M. 2004. Correlation Equation for Predicting Single-Collector Efficiency in Physicochemical Filtration in Saturated Porous Media. Environ. Sci. Technol., 38(2): 529-536.

Koczkur, K.M., Mourdikoudis, S., Polavarapu, L., Skrabalak, S.E. 2015. Polyvinylpyrrolidone (PVP) in nanoparticle synthesis. Dalton Trans., 44: 17883.

Worthen, A.J., Tran, V, Cornell, K.A., Truskett, T.M., Johnston, K.P. 2016. Steric stabilization of nanoparticles with grafted low molecular weight ligands in highly concentrated brines including divalent ions. Soft Matter, 12: 2025-2039.

Xu, X., Xu, N., Cheng, X., Guo, P., Chen, Z., Wang, D. 2017. Transport and aggregation of rutile titanium dioxide nanoparticles in saturated porous media in the presence of ammonium. Chemosphere, 169, 9-17.

Yang, J., Xu, P., Hu, L., Zeng, G., Chen, A., He, K., Huang, Z., Yi, H., Qin, L., Wan, J. 2018. Effects of molecular weight fractionated humic acid on the transport and retention of quantum dots in porous media. Environ. Sci.: Nano, 5: 2699-2711. 
Yao, Q., Luo, Z., Yuan, X., Yu, Y., Zhang, C., Xie, J., Lee, J.Y. 2014. Assembly of Nanoions via Electrostatic Interactions: Ion-Like Behavior of Charged Noble Metal Nanoclusters. Sci. Rep., 4: 3848. Yecheskel, Y., Dror, I., Berkowitz, B. 2018. Silver nanoparticle (Ag-NP) retention and release in partially saturated soil: column experiments and modelling. Environ. Sci.: Nano, 5: 422-435.

Zamborini, F.P., Hicks, J.F., Murray, R.W. 2000. Quantized Double Layer Charging of Nanoparticle Films Assembled Using Carboxylate/($\left(\mathrm{Cu}^{2+}\right.$ or $\left.\mathrm{Zn}^{2+}\right) /$ Carboxylate Bridges. J. Am. Chem. Soc., 122: 4514-4515.

Zhou, J., Ralston, J., Sedev, R., Beattie, D.A. 2009. Functionalized gold nanoparticles: Synthesis, structure and colloid stability. J. Colloid Interf. Sci., 331: 251-262.

Zuber, A., Purdey, M., Schartner, E., Forbes, C., van der Hoek, B., Giles, D., Abell, A., Monro, T., Ebendorff-Heidepriem, H. 2016. Detection of gold nanoparticles with different sizes using absorption and fluorescence based method. Sensor. Actuat. B, 227, 117-127. 